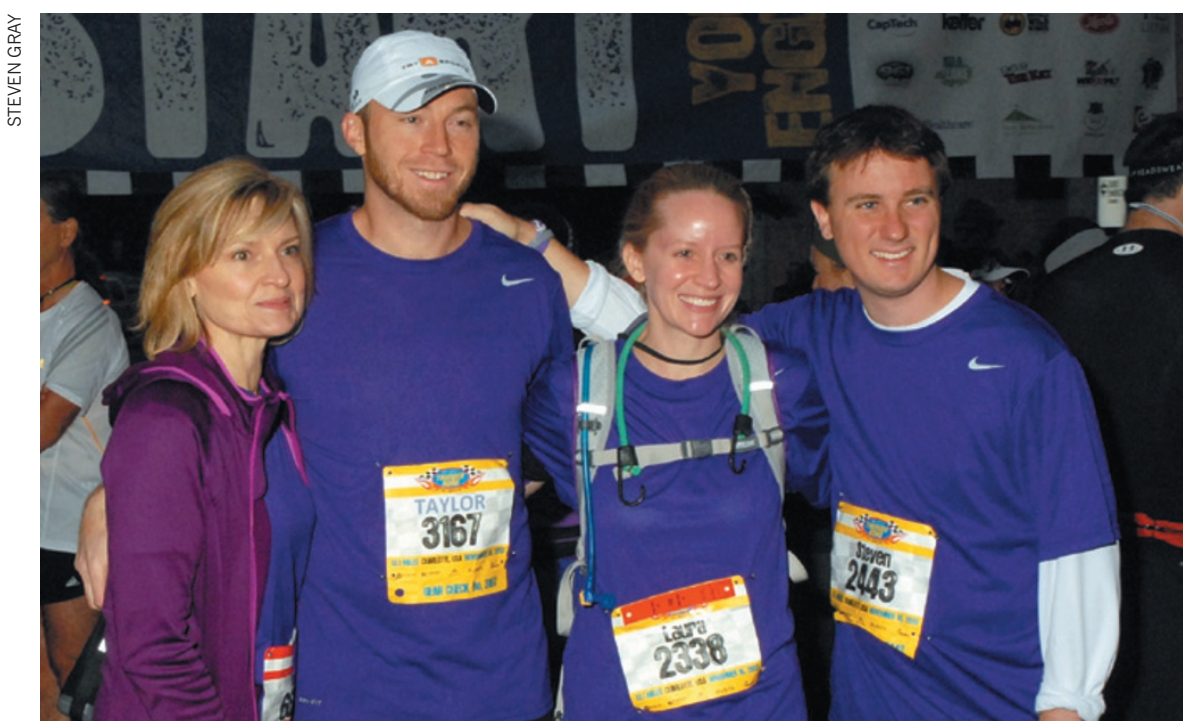

Steven Gray (far right) was inspired to launch a project on giant axonal neuropathy, a rare disease.

the idea that the significance of a project is directly proportional to the number of patients affected," he says.

\section{SECURING FUNDS}

One method for boosting funding opportunities is to look for ways in which a rare disease overlaps with a more common one. Heather Bean, a chemist at Dartmouth College in Hanover, New Hampshire, is using a two-year postdoctoral fellowship from the Cystic Fibrosis Foundation in Bethesda, Maryland, to support her studies of bacterial lung infections associated with cystic fibrosis. But she hopes eventually to expand her funding opportunities by exploring overlaps between cystic fibrosis and a more common ailment, chronic obstructive pulmonary disease. "I'm still committed to looking at cystic fibrosis," she says. "But drawing those links to a bigger, more fundable disease is handy."

Some labs thrive by pulling in grants and fellowships from multiple foundations. Claudio Hetz, co-director of the Biomedical Neuroscience Institute at the University of Chile in Santiago, studies protein folding, which goes awry in several rare diseases including Creutzfeldt-Jakob disease, Huntington's disease and amyotrophic lateral sclerosis. Hetz was worried about finding funds when he left his postdoc in the United States to open his own lab. He applied to a slew of foundations, hoping to get an award from one. He received three grants. "It was the starting point for everything," he says. "It allowed me to build a solid lab really fast."

Hetz rattles off a list of five foundations that he works with, and says that he has forged personal relationships with people at each of them. Some, such as the Michael J. Fox Foundation for Parkinson's Research, based in New York, do more than just hand over money. Hetz says that he contacts a programme officer there when he encounters a technical stumbling block, and the officer works with him to find the right scientist to consult.

Yet there can be drawbacks to foundation grants. The awards are often smaller than government grants - Gray, who now runs his own laboratory at the University of North Carolina in Chapel Hill, says that the largest of his seven foundation grants is still just shy of $\$ 250,000$ a year. His smallest have values of about $\$ 50,000$ per year. And the grants often last only a year or two, creating a sense of instability. Furthermore, foundations rarely pay for full operational costs - such as building maintenance and administrative support - that universities typically take out of government grants. For that reason, universities say that they can lose money on the awards, and sometimes force staff to decline them. Researchers who are interested in competing for foundation money would therefore do well to check with their institutions to find out if they can accept the funds (see Nature 504, 343; 2013).

Foundations also expect their grant recipients to remain focused on the goal of helping patients. Gray warns applicants to his lab that this will sometimes mean dropping scientifically interesting experiments if they do not obviously contribute to the project's main mission. "We really make sure that everything we're doing is in the best interest of the people that are funding us," he says.

Gray is comfortable with that compromise. Last year, he applied to the FDA for approval to conduct a GAN clinical trial. He counts several people with GAN and their families among his friends. His voice is strained when discussing the recent death of an adult with the condition whom he met at that original meeting. "It's tough," he says. "You're always trying to work a little harder." -

Heidi Ledford reports for Nature from Cambridge, Massachusetts.

\section{GENDER}

\section{Female speakers}

Having at least one woman on the speakerrecruiting team for a scientific conference boosts the number of female speakers, finds a 7 January study (A. Casadevall and J. Handelsman mBio http://doi. org/qsh; 2014). The authors examined 460 symposia with a total of 1,845 speakers at two annual meetings sponsored by Washington DC's American Society for Microbiology in 2011-2013. They focused on 104 all-male convener teams and 112 with at least one woman. When at least one woman was on the team, the proportion of female speakers rose from an average of $25 \%$ to $43 \%$. Co-author Arturo Casadevall, a microbiologist at the Albert Einstein College of Medicine in New York, says that early-career female scientists can benefit from volunteering to be speaker recruiters.

\section{SALARIES}

\section{Living in the present}

Prospective biomedical postgraduate students decide whether to enrol on the basis of current salaries rather than potential future earnings, says a study out on 23 December (M. E. Blume-Kohout and J. W. Clack PLoS ONE http://doi. org/qsq; 2013). Data for 1996-2010 showed that postgraduate enrolment for a given year rose by $2.9-3.9 \%$ when relative wages for biomedical-science posts rose by $1 \%$. But enrolment in a given year did not correspond to salary changes six years later, around graduation time. Prospective students should consider effects on salary trends, such as dips in agency budgets, says co-author Meg Blume-Kohout, a senior research economist at the New Mexico Consortium in Albuquerque.

\section{FEMALE RESEARCHERS}

\section{Ireland lines up grants}

The Irish government plans to launch oneand two-year postdoctoral fellowships, worth up to $€ 185,000$ (US\$252,000) each, to prompt early-career female researchers to stay in or return to the scientific workforce after childcare or other breaks. Science Foundation Ireland (SFI) in Dublin will announce the 20 or so Advance Fellowship grants by June, says Elena Martines, the SFI's scientific programme officer. Currently, 35\% of SFI-funded Irish postdocs and $20 \%$ of SFI-funded academic researchers are women, says Martines. "This is a very bold programme," she says, noting that few similar initiatives exist. 